\title{
MOTIVATOR PROGRAM IMPLEMENTATION FOR VOLUNTARY BLOOD DONORS: "RED JUNE - USE YOUR INNER BEAUTY"
}

\author{
Pablo Henrique Delmondes ${ }^{a}$, \\ ${ }^{a}$ Coordenador e professor no curso de Tecnologia em Estética e Cosmética e coordenador do grupo \\ de pesquisa PECIEC (Pesquisa em Ciências Estéticas e Cosméticas) das Faculdades Unidas do Vale \\ do Araguaia/UNIVAR
}

\begin{abstract}
.
Due the need to recruit new volunteer blood donors and consequently keep the blood bags stock in collection centers of several countries, especially those in development, Technology Course in Aesthetics and Cosmetics coordination of the Faculdades Unidas do Vale do Araguaia (UNIVAR), Barra do Garças, MT, Brazil, created the "Red June - Use Your Inner Beauty" program, which aims to motivate and educate people about the importance of donating blood voluntarily to save lives. The program aims to cover several countries and will take to the community various activities, such as motivational lectures and informative pamphlets distribution, as well as other actions. The program is intended to draw the attention of the whole world to the need for voluntary unpaid blood donation.
\end{abstract}

\section{Introduction}

Since 2004, blood donors are celebrated annually in many countries on June 14, commemorating the birth date of Karl Landsteiner, the most famous Nobel Prize winner of the 1930s in the field of blood transfusion that discovered ABO blood groups (1901) and codiscovered the Rhesus D (now called RH: 1) blood group (1940). This event, launched worldwide has prestigious patrons: the WHO, International Federation of Red Cross and Red Crescent Societies, the International Federation of Blood Donors and outhers [1,2].

Human blood is an essential element of human life and there are no substitutes. The availability of safe blood and blood products is a critical component in improving health care. Millions of lives are saved each year through blood transfusions [3].

The need for blood is growing day by day as a result of advancement in clinical medicine. The collection of blood only from voluntary and unpaid blood donors from low-risk populations is an important measure to ensure the safety, quality, availability and accessibility of blood transfusion [4].

According to the World Health Organization (WHO), 108 million blood donations occur annually from all types of donors (unpaid volunteers, substitutes and paid) and $65 \%$ of blood transfusions in low-income countries are offered to children under the age of five. About $50 \%$ of blood donations are collected 
Section: LAWSCI-02: Challenges in Law, Technology, Life, and Social Sciences, UPV/EHU, Bilbao,

in high-income countries, home to $15 \%$ of the world's population [5].

The voluntary donor of unpaid blood is a person who donates blood and receives no payment, either in the form of money or of any kind that may be considered a substitute for money. A surrogate donor is also an unpaid donor who donates blood to a particular patient in an emergency. Substitute donors are usually family members, colleagues, or friends of the patient in question. The paid donor receives monetary payment for a blood donation. Although it is not in all countries that allow paid blood donation, most donors in the world are still substitutes or paid [6].

It is important to develop campaigns to voluntarily recruit and retain unpaid blood donors in order to sustainably maintain blood bags in blood banks. The recruitment program needs to address factors that limit blood donation, such as fear of needles and stigma associated with blood donation, which are the biggest challenges for recruiting novice and repeat donors $[7,8]$.

The availability of blood bags is critical because of the high proportion of patients with renal insufficiency, some cases of childbirth, surgeries and incidents that need to get blood as fast as possible to save the life of these cases [5, $9,10]$.

The World Health Organization (WHO) has estimated that donation $1 \%$ of a country's population is the minimum blood needed to meet the basic blood needs of a nation. However, less than $1 \%$ of populations in many countries around the world, especially developing countries, donate blood [11]. The year 2020 is the WHO target year for all countries to obtain $100 \%$ of the blood supply from unpaid volunteer donors [5].

\section{Blood donation overview around the world}

In Brazil, donating blood is based on voluntary donor decision making. According to information from the Ministry of Health, in the country are collected 3.5 million blood bags per year; nevertheless, the ideal amount of donations is around 5.7 million; Additionally, although $1.9 \%$ of Brazilians are classified as donors, the level of donation frequency is low, since donation is more common only once a year [12].

In Germany, as in Brazil, blood donations are voluntary, although some donation services offer a grant of 20 euros to cover travel expenses for the blood center [13].

In countries such as Nigeria and other developing countries, in addition to the shortage of donors, there is a shortage of low-risk blood in view of the various diseases that can be transmitted by blood transfusion [11].

In the Kingdom of Saudi Arabia (KSA), most blood is provided by substitute donors rather than paid blood donor volunteers [6]. In Pakistan, more than 1.5 million liters of blood are collected each year. Among them, about $65 \%$ are from substitute donors, $25 \%$ from voluntary donors and about $10 \%$ from professional donors [14].

In India, 8.01 million units were collected by the public sector and blood banks registered in the years 2009 and 2010. In public and charity blood banks, currently $76.1 \%$ of blood is collected through voluntary blood donation [15].

\section{Social marketing as alternative for population awareness}

Since the 1950s, hundreds of studies conducted around the world have investigated factors that motivate and discourage blood donation. Given the large number of studies that still blend findings, the synthesis of results is essential for both researchers and strategists within blood collection agencies $[16,17]$.

Among the motivating strategies for blood donors, social marketing is unleashed. Social marketing can be understood as the use of commercial marketing techniques for the purpose of influencing a particular public to voluntarily accept, modify, reject or abandon certain behavior in favor of social welfare, which may be a cause such as blood donation, for example. It should be noted that this change in behavioral patterns starts at individual limits and evolves to collective levels. In sum, social marketing induces a behavioral change in individuals in an attempt to achieve change, which focuses on the society's thought patterns and their respective evolution, in order to meet the group's emerging 
Section: LAWSCI-02: Challenges in Law, Technology, Life, and Social Sciences, UPV/EHU, Bilbao, Spain, 2018

needs, through variations relationships between people, groups, organizations and societies [18].

\section{Program Implementation "Red June: Use Your Inner Beauty"}

Based on all the problems encountered in relation to voluntary blood donation, the difficulty in obtaining low-risk blood in some countries makes it necessary to implement motivational programs for blood donors.

"Red June: Use Your Inner Beauty" is a motivational program for volunteer blood donors, which was conceived by Aesthetic and Cosmetic Technology Course coordination of the Faculdades Unidas do Vale do Araguaia (UNIVAR), located in the Barra do Garças municipality, Mato Grosso, Brazil. The program aims to raise awareness and motivate the population, not only Brazilian, but worldwide, about the importance of voluntary blood donation to save human lives, especially in low- income countries where blood donation deficits are higher.

"Red June: Use Your Inner Beauty" program will work by promoting lectures at schools and universities as well as working with the distribution of informative and motivational pamphlets and individual orientations among the popular.

The program will begin in June of this year in Brazil and will have the voluntary participation of professors and academics of the Technology Course in Aesthetics and Cosmetics and later will be extended to the public interested in contributing to public information and guidance to the population.

Contact with other higher education institutions of different nationalities is already being made to join and implement the program in their respective institutions, since the main objective of the program is to reach the largest number of people in the world.

\section{Conflicts of Interest}

The author declare no conflict of interest

\section{References}

1. Garraud, O. Celebrating donors and the World Blood Donor Day 2018. 2018.

2. Marwaha, N. Voluntary blood donation in India: Achievements, expectations and challenges. Asian journal of transfusion science, 2015, 9,S1..

3. Agrawal, A. et al. Knowledge, attitude and practices of people towards voluntary blood donation in Uttarakhand. Asian journal of transfusion science, 2013, 7, 59.

4. Lowkik, E. et al. Knowledge, attitudes and practices surveys of blood donation in developing countries. Vox sanguinis, 2012, 103, 64-74.

5. Ouhbi, S. et al. Free blood donation mobile applications. Journal of medical systems, 2015, 39, 52.

6. Alam, M.; Masalmeh, D. B. D. Knowledge, attitudes and practices regarding blood donation among the Saudi population. Saudi Medical Journal, 2004, 25, 318-321. 
Section: LAWSCI-02: Challenges in Law, Technology, Life, and Social Sciences, UPV/EHU, Bilbao,

7. Mauka, W. I. et al. Factors associated with repeat blood donation at the Northern Zone Blood Transfusion Centre in Tanzania. Journal of blood transfusion, 2015, 2015.

8. Jaafar, J. R. Chong, S. T.; Alavi, K. Experience as factors associated with repeat blood donation among university students in Malaysia. Southeast Asian Journal of Tropical Medicine and Public Health, 2017, 48, 1118-1126.

9. Ouhbi, S. et al. Compliance of blood donation apps with mobile OS usability guidelines. Journal of medical systems, 2015, 39, 63.

10. Ali, R. S. et al. Blood bag: A web application to manage all blood donation and transfusion processes. In: Wireless Communications, Signal Processing and Networking (WiSPNET), 2017 International Conference on. IEEE, 2125-2130, 2017.

11. Salaudeen, A. G. et al. Community survey on blood donation practices in a northern state of Nigeria. Journal of preventive medicine and hygiene, 2011, 52.

12. Barboza, S. I. S.; Costa, F. J. Marketing social para doação de sangue: análise da predisposição de novos doadores. Cadernos de Saúde Pública, 2014, 30, 1463-1474.

13. Greinacher, A. et al. A population-based longitudinal study on the implication of demographic changes on blood donation and transfusion demand. Blood advances, 2017, 1, 867-874.

14. Ahmed, Z. et al. Knowledge, attitude and practices about blood donation among undergraduate medical students in Karachi. Journal of Infectious Diseases and Therapy, 2014, 2, 53-59.

15. Mullah, F. Study of knowledge, perceptions and practices related to blood donation among the healthcare support staff of a tertiary care hospital in Gujarat, India. Online Journal of Health and Allied Sciences, 2013, 12.

16. Bednall, T. C. et al. A systematic review and meta-analysis of antecedents of blood donation behavior and intentions. Social science \& medicine, 2013, 96, 86-94.

17. Mousavi, F. et al. Knowledge, attitude and practice towards blood donation in Iranian population. Transfusion Medicine, 2011, 21, 308-317.

18. Pereira, J. R. et al. To donate or not donate, that is the question: an analysis of the critical factors of blood donation. Ciencia \& saude coletiva, 2016, 21, 2475-2484. 